\title{
Toluene concentrations in the blood and alveolar air of workers during the workshift and the morning after
}

\author{
F BRUGNONE, ${ }^{1}$ E DE ROSA, ${ }^{2}$ L PERBELLINI, ${ }^{1}$ AND GB BARTOLUCCI ${ }^{2}$
}

From the Istituto di Medicina del Lavoro dell'Università di Verona, 37134 Verona, and Istituto di Medicina del Lavoro dell'Università di Padova, 35127 Padova, Italy

ABSTRACT Occupational toluene exposure was studied during the workshift and the morning after $\frac{\mathbb{D}}{7}$ by the analysis of environmental air, alveolar air, and blood. Environmental toluene exposure was measured by both continuous and instantaneous sampling. Instantaneous environmental toluene ${ }_{-}^{\omega}$ concentrations correlated better with alveolar toluene concentrations $(r=0.94 ; n=155)$ than with blood toluene concentrations $(r=0.71 ; n=52)$. Continuous environmental toluene concentrations。 correlated better with blood toluene concentrations $(r=0.84 ; n=65)$ than with alveolar toluene $e_{-}^{\supset}$ concentrations $(r=0.52 ; n=46)$. During the workshift and the morning after, blood and alveolar toluene concentrations correlated significantly with each other $(r=0.75 ; n=66$ and $r=0.67 ; n$ ? $=52$ ). In a group of workers who were exposed to a mean environmental toluene concentration of $146 \mu \mathrm{g} / 1$ the concentrations of toluene in the alveolar air and blood the morning after were $3 \cdot 2 \mu \mathrm{g} / \mathrm{l}_{\overrightarrow{0}}$ $(\mathrm{SD}=1.7)$ and $27.5 \mu \mathrm{g} / \mathrm{l}(\mathrm{SD}=12.7)$ respectively. With regard to the morning after toluene $\infty_{\infty}^{\circ}$ determinations, blood concentrations correlated $(\mathrm{r}=0.52 ; \mathrm{n}=52 ; \mathrm{p}<0.001)$ better than the alveolar concentrations with the corresponding afternoon values $(r=0.36 ; n=52 ; p<0.01)$. The decline of the toluene concentrations from the end of one workshift to the start of the next exposure indicated a mean toluene half life of 3.8 hours in the alveolar air and of 4.5 hours in blood and therefore the 17 hour interval between two consecutive workshifts was insufficient for the complete $\frac{}{\mathbb{Q}}$ elimination of absorbed toluene.

The metabolism of toluene and the urinary excretion of its metabolites in relation to exposure have been extensively studied by industrial hygienists and occupational physicians. On the other had, little interest has been focused on the correlations of the concentration of toluene in the plant atmosphere with its concentration in breath and blood during the workshift and the morning after (before a new exposure). Blood and alveolar toluene concentrations have been generally studied in individuals experimentally exposed. ${ }^{1-4}$ With regard to the blood and alveolar concentrations of toluene few data have been collected from workers occupationally exposed. ${ }^{5-11}$

In the International Workshop on Toxicology of Benzene $^{12}$ it was stated, with regard to the breath sampling of benzene: "It is accepted that samples taken immediately before a shift best reflect exposure during the previous shift and earlier periods. Samples taken at the end of work, though providing greater

Accepted 24 March 1985 sensitivity, are greatly influenced by exposure toward the end of the shift."

Regarding occupational toluene exposure Lauwerys reported that not enough investigations have been performed to evaluate whether analysis of expired air (or blood) collected 16 hours after the enc. of exposure - that is, before the next shift-can pro? vide, as for benzene, an estimate of the magnitude op the previous day's intake of toluene. ${ }^{13}$ The purpose of the present study has been to investigate whether thes analysis of the alveolar air and blood collected the morning after the occupational toluene exposure $(1 \overline{\mathrm{G}}$ hour after the end of exposure) may be reliably used for evaluating previous exposure.

\section{Materials and methods}

In workers employed in different workplaces (roto gravure, printing, shoe factories) we studied exposure to toluene by examining environmental air, alveola air, and blood. 


\section{Environmental air samples}

Two different types of atmospheric samples, instantaneous and continuous, were collected. Continuous samples were collected for the entire workshift (7 hours) by means of portable pumps (Dupont) and charcoal tubes to estimate the exposure of 65 workers. For each worker during the entire workshift, two samples were collected, each lasting three and a half hours. The sampling flow rate was $11 / \mathrm{min}$. Gas chromatographic determination of toluene was carried out, after desorption with carbon disulphide, according to the NIOSH method. ${ }^{14}$ All 65 workers supplied one blood sample, but not always one alveolar air sample, at the end of the continuously tested workshift. Instantaneous environmental air samples were taken from the breathing zone of each worker at the place of the alveolar air sampling. Instantaneous environmental sampling was carried out both at random times during the workshift and at the end of work. A total of 155 instantaneous environmental air samples were collected simultaneously with the alveolar air samples. Instantaneous environmental air samples were collected into glass tubes similar to those used for alveolar air, using a manual pump.

\section{Alveolar air samples}

Alveolar air samples were collected at random times during the workshift and at the end of the workshift from more than 100 workers. On the morning after, 52 workers supplied one alveolar air sample before the start of the workshift. The alveolar air samples were taken in the workplace during the shift and in the plant infirmary the morning after. Alveolar air samples were collected into stoppered glass tubes with screw caps at both ends, with an inside volume of $70 \mathrm{ml}$. After a normal inspiration, the workers gave a forced expiration, keeping the glass tube between their lips. The tube was immediately sealed with caps at the end of the expiration. Until analysis, all the air samples were kept at a temperature of $60^{\circ} \mathrm{C}$.

\section{Venous blood samples}

Blood samples were collected from 66 workers at the end of the workshift (before leaving the workplace), and from 52 workers the morning after. One instantaneous environmental air sample and one alveolar air sample were generally collected with each blood sample. The blood samples, which were put in glass vials, were analysed by a head space technique. Three millilitres of heparinised venous blood were injected into $12 \mathrm{ml}$ glass vials provided with a screw cap and a Teflon membrane. For the analysis, $1 \mathrm{ml}$ of the air from the head space was injected, with a heated gas tight syringe, into the gas chromatograph. The glass vials were kept at $5^{\circ} \mathrm{C}$ during the journey from the factories to the laboratory and then put in a room heated at $37^{\circ} \mathrm{C}$ for two to three hours before analysis.

The concentrations of toluene was measured in the air and blood samples using a C Erba Fractovap 2350 gas chromatograph, equipped with FID, steel column $(200 \mathrm{~cm} \times 2 \mathrm{~mm}$ ID), packed with Apiezon L $10 \%$ on Supelcoport 80-100 mesh; temperature: oven $130^{\circ} \mathrm{C}$, detector and injector $210^{\circ} \mathrm{C}$; carrier gas: nitrogen; flow rate: $20 \mathrm{ml} / \mathrm{min}$.

Standard samples were obtained by adding known amounts of toluene into glass bottles of about 51 provided with a perforable screw cap and Teflon membrane. Standard samples were kept in the oven at $80^{\circ} \mathrm{C}$ for at least one hour before testing. Samples of $1 \mathrm{ml}$ were injected into the gas chromatograph with a heated syringe. The determination limit was $0.5 \mu \mathrm{g} / 1$, which corresponded to a peak of $1 \mathrm{~mm}$ of height.

All toluene determinations were carried out within two to six hours of collection. As data usually were not normally distributed, associations were measured with the Spearman rank correlation coefficient.

\section{Results}

\section{TOLUENE DETERMINATIONS DURING THE} WORKSHIFT

Figures 1-4 show the correlations between alveolar and blood toluene concentrations and environmental toluene concentrations; the mean, SD, and median of the individual data are also shown. The Spearman rank correlation coefficients were 0.87 ( $p<0.001$ ), $0.61(\mathrm{p}<0.001)$, and $0.31(\mathrm{p}<0.05)$ respectively (figs 1-3).

An examination of figs 1-4 shows that the alveolar toluene concentrations correlated with the instantaneous environmental toluene concentrations (fig 1: $r=0.94$ ) more strongly than with the environmental toluene concentrations measured continuously during the entire workshift (fig 3: $r=0.52$ ). On the other hand, the blood toluene concentrations correlated less well with the instantaneous environmental toluene concentrations (fig 2: $r=0.71$ ) than with the environmental toluene concentrations measured continuously during the workshift (fig 4: $r=0.84$ ).

According to the slopes of the regression lines, the ratio between alveolar $(\mathrm{Ca})$ toluene concentrations and environmental $(\mathrm{Ci})$ toluene concentrations $(\mathrm{Ca} / \mathrm{Ci}$ ) was $0.33-0.30$ (figs 1 and 3 ); the ratio between blood $(\mathrm{Cb})$ toluene concentrations and environmental toluene concentrations $(\mathrm{Cb} / \mathrm{Ci})$ was $2 \cdot 1-2 \cdot 6$ (figs 2 and 4).

Alveolar and blood toluene concentrations measured at the end of exposure were found to correlate significantly with each other (fig $5: r=0 \cdot 76 ; n=66$; $\mathrm{p}<0.001)$. According to the slope of the regression line, the ratio between blood and alveolar toluene concentrations $(\mathrm{Cb} / \mathrm{Ca})$ was equal to 4.0 (fig 5). The 


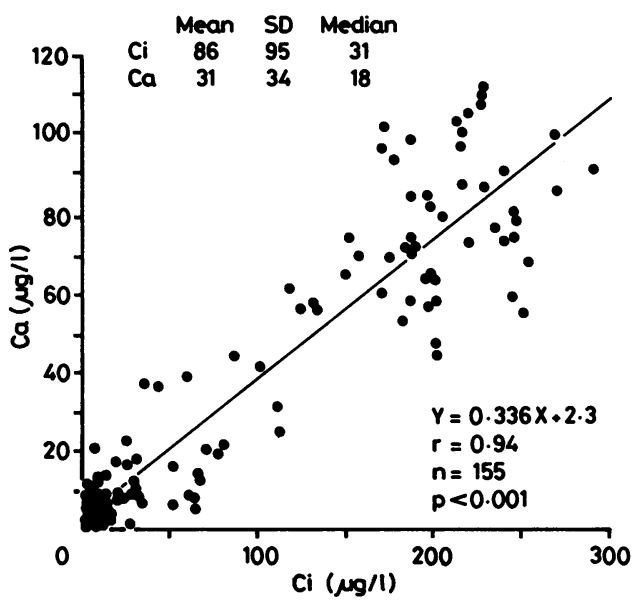

Fig 1 Correlation between alveolar $(\mathrm{Ca})$ and environmental (Ci) toluene concentrations measured by instantaneous samples collected at random times during workshift and at end of exposure.

mean of the individual $\mathrm{Cb} / \mathrm{Ca}$ ratios was $9 \cdot 4(\mathrm{SD}=$ 11.4).

\section{TOLUENE DETERMINATIONS THE MORNING} AFTER

Fifty two workers were examined both at the end of the workshift and the morning after. Table 1 shows that the mean alveolar toluene concentration $(3.2 \mu \mathrm{g} / 1)$ was similar to the mean environmental toluene concentration measured in the infirmary of the factory $(4.0 \mu \mathrm{g} / \mathrm{l})$ where the morning after biological samples were taken. The toluene concentrations

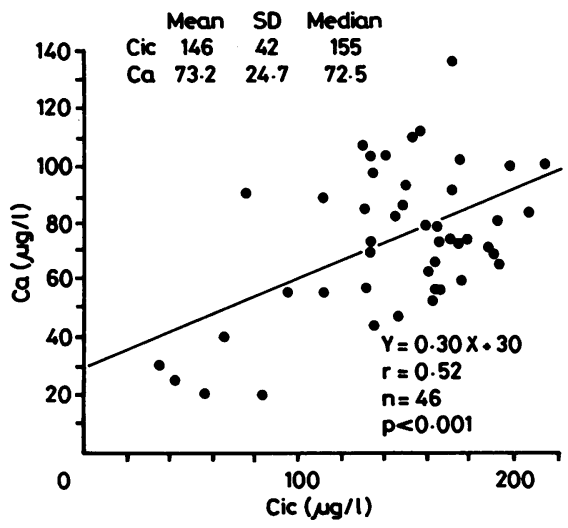

Fig 3 Correlation between alveolar toluene concentrations measured by instantaneous samples collected at end of workshift ( $\mathrm{Ca}$ ) and environmental toluene concentrations measured by continuous samples collected during the seven hours of entire workshift (Cic).



Fig 2 Correlation between blood ( $\mathrm{Cb}$ ) and instantaneous environmental (Ci) toluene concentrations measured at end $\mathrm{G}$ of workshift.

ranged between 0.5 and $7 \mu \mathrm{g} / 1$ in the alveolar air and between 0.5 and $7.6 \mu \mathrm{g} / 1$ in the infirmary atmosphere

The morning alveolar toluene concentration showed the best correlation with the instantaneous $\vec{c}$ environmental toluene concentration measured at the end of the workshift $(r=0.45 ; n=52 ; p<0.001$ table 2). It corresponded, on average, to $4 \cdot 7 \%$ (SD $=0$ $2 \cdot 7 \%$; range $=1-14 \%$ ) of the afternoon alveolar tolu ene concentration.

The blood toluene concentration measured the morning after was, on average, $27.5 \mu \mathrm{g} / 1$, with a rangeo between 9 and $66 \mu \mathrm{g} / 1$. It correlated with the afternoon $\overrightarrow{\overrightarrow{5}}$ blood toluene concentration more strongly than with any other afternoon toluene concentration $(r=0.52$;

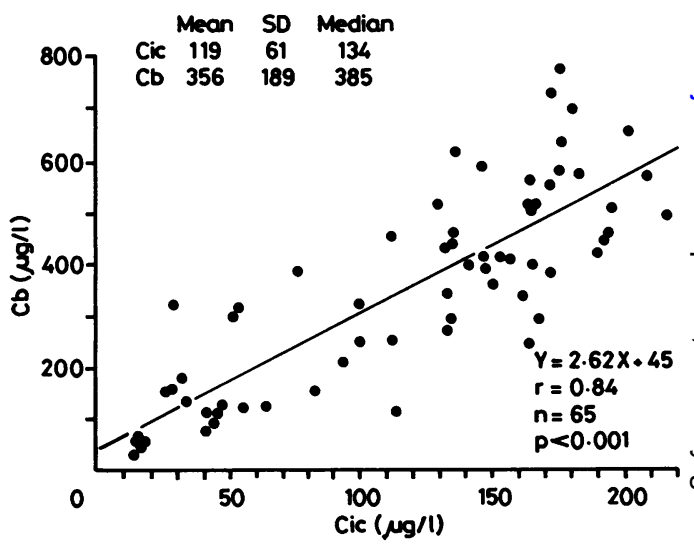

Fig 4 Correlation between blood toluene concentrations measured in venous blood samples collected at end of workshift $(\mathrm{Cb})$ and environmental toluene concentrations measured during the seven hours of entire workshift (Cic). 




Fig 5 Correlation between alveolar (Cal) and blood (Cb1) toluene concentrations measured at end of workshift.

$\mathrm{n}=52 ; \mathrm{p}<0.001 ;$ table 2).

The morning blood toluene concentration corresponded, on average, to $7 \cdot 2 \%(\mathrm{SD}=3 \cdot 1 \%$; range $=$ $2-15 \%)$ of the afternoon blood toluene concen- tration. It also correlated significantly with the alveolar toluene concentration measured at the same time $(r=0.67 ; n=52 ; p<0.001 ;$ table 2$)$. The mean of the individual ratios between blood and alveolar toluene concentrations measured the morning after was $10 \cdot 5(\mathrm{SD}=7 \cdot 6)$.

\section{Discussion}

Our data show that the alveolar toluene concentration, measured during the workshift, correlated significantly with the environmental toluene concentration measured by instantaneous samples collected simultaneously (fig $1: \mathrm{r}=0.94$ ). It is interesting to note that the alveolar toluene concentration, measured only at the end of the workshift, correlated with the environmental toluene concentration measured during the entire workshift (fig 3: $r=0.52$ ). This last correlation is a little surprising in the light of the previous studies. ${ }^{1213}$ Nevertheless it must be pointed out that in the present study the environmental toluene concentrations measured at the end of the workshift (by instantaneous samples) and during the entire workshift (by continuous samples) were significantly correlated $(r=0.56 ; n=46 ; p<0.001)$.

Table 1 Concentrations of toluene ( $\mu \mathrm{g} / \mathrm{l})$ in environmental air, alveolar air, and blood during the workshift and the morning after

\begin{tabular}{lllllllll}
\hline & Ciil & Cicl* & Cal & CbI & Cii2 & Ca2 & Cb2 & \\
\hline Mean & 201 & 146 & $72 \cdot 0$ & 412 & $4 \cdot 0$ & $3 \cdot 2$ & $27 \cdot 5$ \\
SD & 53 & 42 & $24 \cdot 9$ & 158 & $3 \cdot 2$ & $1 \cdot 7$ & $12 \cdot 7$ \\
Range & $77-308$ & $36-215$ & $21-134$ & $89-765$ & $0 \cdot 5-7 \cdot 6$ & $0 \cdot 5-7$ & $9-66$ \\
Median & 210 & 155 & $71 \cdot 5$ & 412 & $3 \cdot 2$ & $3 \cdot 0$ & $25 \cdot 5$ \\
\hline
\end{tabular}

Ciil = Instantaneous environmental toluene concentration measured at end of workshift.

$\mathrm{Cicl}^{*}=$ Environmental toluene concentration measured continuously during entire workshift in 46 workers only (not in 52).

$\mathrm{Ca}$ l = Alveolar toluene concentration measured at the end of workshift.

$\mathrm{Cb} 1=$ Blood toluene concentration measured at end of workshift.

Cii2 = Instantaneous environmental toluene concentration measured in infirmary the morning after.

$\mathrm{Ca} 2$ = Alveolar toluene concentration measured the morning after.

$\mathrm{Cb} 2=$ Blood toluene concentration measured the morning after.

Table 2 Correlations between morning alveolar (Ca2) and blood (Cb2) toluene concentrations and afternoon toluene concentrations

$\begin{array}{lllll}\mathrm{Ca} 2=0.010 \mathrm{Cic} & +1.8 ; & \mathrm{r}=0.28 ; & \mathrm{n}=46 ; \mathrm{p}<0.1 ; & (\mathrm{rs}=0.19 ; \mathrm{p}=\mathrm{NS}) \\ \mathrm{Ca} 2=0.014 \mathrm{Cii} & +0.3 ; & \mathrm{r}=0.45 ; & \mathrm{n}=52 ; \mathrm{p}<0.001 ; & (\mathrm{rs}=0.42 ; \mathrm{p}<0.01) . \\ \mathrm{Ca} 2=0.024 \mathrm{Ca} & +1.4 ; & \mathrm{r}=0.36 ; & \mathrm{n}=52 ; \mathrm{p}<0.01 ; & (\mathrm{rs}=0.42 ; \mathrm{p}<0.01) \\ \mathrm{Ca} 2=0.004 \mathrm{Cb} & +1.4 ; & \mathrm{r}=0.42 ; & \mathrm{n}=52 ; \mathrm{p}<0.01 ; & (\mathrm{rs}=0.45 ; \mathrm{p}<0.001) \\ \mathrm{Cb} 2=0.10 \mathrm{Cic} & +12 ; & \mathrm{r}=0.36 ; & \mathrm{n}=46 ; \mathrm{p}<0.05 ; & (\mathrm{r}=0.26 ; \mathrm{p}<0.1) . \\ \mathrm{Cb} 2=0.07 \mathrm{Cii} & +13 ; & \mathrm{r}=0.30 ; & \mathrm{n}=52 ; \mathrm{p}<0.05 ; & (\mathrm{rs}=0.24 ; \mathrm{p}<0.1) . \\ \mathrm{Cb} 2=0.14 \mathrm{Ca} & +17 ; & \mathrm{r}=0.27 ; & \mathrm{n}=52 ; \mathrm{p}<0.05 ; & (\mathrm{rs}=0.30 ; \mathrm{p}<0.05) . \\ \mathrm{Cb} 2=0.04 \mathrm{Cb} & +10 ; & \mathrm{r}=0.52 ; & \mathrm{n}=52 ; \mathrm{p}<0.001 ; & (\mathrm{rs}=0.51 ; \mathrm{p}<0.001) \\ \mathrm{Cb} 2=5.1 \mathrm{Ca} 2 & +11 ; & \mathrm{r}=0.67 ; & \mathrm{n}=52 ; \mathrm{p}<0.001 ; & (\mathrm{rs}=0.73 ; \mathrm{p}<0.001) .\end{array}$

In parentheses: $\mathbf{r s}=$ rank correlation coefficient.

$\mathrm{Cic}=$ Environmental toluene concentration measured continuously during entire workshift.

$\mathrm{Cii}=$ Instantaneous environmental toluene concentration measured at end of workshift.

$\mathrm{Ca}=$ Alveolar toluene concentration measured at end of workshift.

$\mathrm{Cb}=$ Blood toluene concentration measured at end of workshift. 


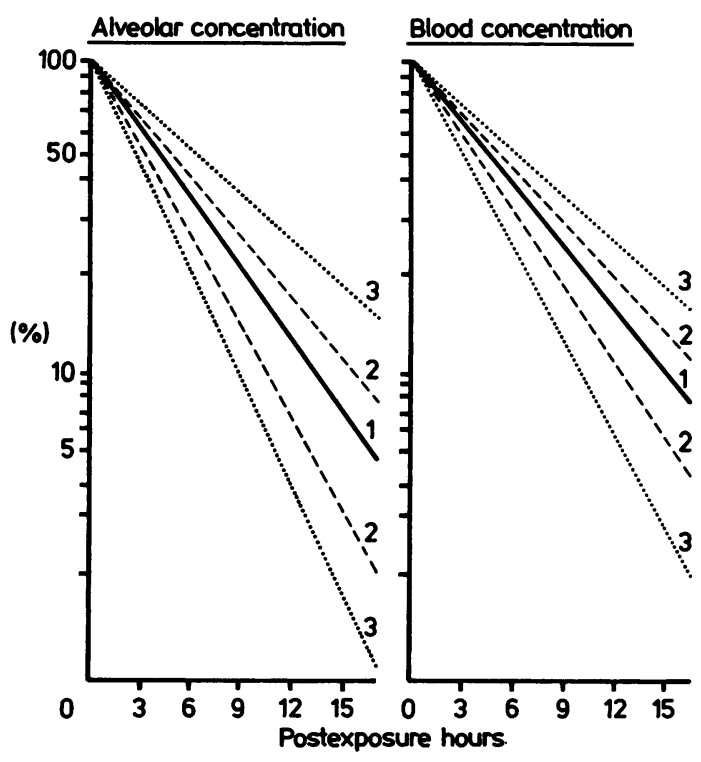

Fig 6 Rate constants $(K)$ of toluene decline in alveolar air and blood, 17 hours after end of exposure: $K 1=$ mean; $K 2=S D ; K 3=$ range.

Alveolar concentration: $K 1=-0 \cdot 180 / h(t / 2=3 \cdot 8 h)$;

$K 2=-0 \cdot 153:-0 \cdot 230 / h(t / 2=4 \cdot 5-3 \cdot 0 h)$;

$K 3=-0 \cdot 116:-0 \cdot 271 / h(t / 2=6 \cdot 0-2 \cdot 6 h)$.

Blood concentration: $K 1=-0 \cdot 155 / h(t / 2=4 \cdot 5 h)$;

$K 2=-0 \cdot 134:-0 \cdot 186 / h(t / 2=5 \cdot 2-3 \cdot 7 h)$;

$K 3=-0 \cdot 112:-0 \cdot 230 / h(t / 2=6 \cdot 2-3 \cdot 0 h)$.

According to the slope of the regression lines in figs 1 and 3, the alveolar toluene concentrations corresponded, on average, to $30-33 \%$ of the environmental concentrations. In volunteers experimentally exposed to toluene the alveolar toluene concentration was found to be between $15 \%$ and $20 \%^{1}$ and $23-28 \%{ }^{4}$ at rest and during physical exercise of $50 \mathrm{~W}$, between 31 and $34 \%{ }^{1}$ and $39-47 \%{ }^{4}$ of the environmental concentration.

At the end of exposure, the concentration of toluene in blood was, on average, 2.1-2.6 times higher than the environmental concentration (slopes in figs 2 and 4) and four times higher than the alveolar concentration (slope in fig 5).

In a previous paper we reported an experimental value of $\mathrm{Cb} / \mathrm{Ci}$ and $\mathrm{Cb} / \mathrm{Ca}$ ratios of 2.97 and 8.1 respectively. ${ }^{9}$ In venous blood of volunteers exposed to $300 \mu \mathrm{g} / \mathrm{l}$ of toluene the $\mathrm{Cb} / \mathrm{Ci}$ ratio ranged between 1.3 and 1.7 at rest, and between 2.6 and 4.0 during physical exercise of $50 \mathrm{~W} .{ }^{4}$ The corresponding $\mathrm{Cb} / \mathrm{Ca}$ ratios were 4.8-6.6 at rest and 6.9-10.0 during exercise. These are comparable with our findings.

The toluene concentration in the alveolar air samples collected the morning after was $3 \cdot 2 \mu \mathrm{g} / 1$ similar to that found in the air of the infirmary $(4.0 \mu \mathrm{g} / \mathrm{l})$ in which the workers provided the biological samples. These findings suggest that the morning alveolar toluene concentrations were not due to toluene in the air of the infirmary since for this to happen, the toluene concentration should have been much higher than the alveolar concentration $(\mathrm{Ca} / \mathrm{Ci}=\mathbf{0 . 3})$. It is more reasonable to argue that the morning alveolar toluene concentration expressed the respiratory elimination of the toluene absorbed the previous afternoon, rather than the absorption of the toluene in the infirmary.

On the other hand, it is impossible to say whether the infirmary toluene concentration was completely due to the pollution from the plant or, even partly, to the toluene eliminated by the workers. Krotoszynski et al reported that in urban populations the expired air contained toluene with a mean concentration of $8.4 \mathrm{ng} / 1$ (range $4-17.7 \mathrm{ng} / \mathrm{l}$ ) in $100 \%$ of the samples studied. ${ }^{15}$ These findings clearly suggest that toluene can be a ubiquitous pollutant but at a concentration much lower than that which we found in the infirmary and the morning alveolar air.

The toluene concentration measured in the alveolar air collected the morning after corresponded to $4.7 \%$ of that determined in the alveolar air at the end of exposure, with a range between 1 and $14 \%$. For the 17 hour interval between the end of work and the morning after, we can calculate a mean rate constant (k) of respiratory toluene elimination equal to -0.180 an hour, with a range between -0.116 and -0.271 an hour (fig 6). This implies a mean half life of toluene in alveolar air of 3.8 hours $(S D=0.7 \mathrm{~h}$ ) with a range of 6-2.6 hours, respectively.

The morning blood toluene concentration corresponded to $7 \cdot 2 \%$ of the concentration measured at the end of exposure, with a range $2 \%$ and $15 \%$. It can be calculated that during the 17 hour interval between afternoon and the morning after, the rate constant of toluene decline in blood ranged between -0.230 and -0.112 per hour, with a mean rate constant of $-0 \cdot 155$ (fig 6).

The corresponding half lives ranged between 3 and 6.2 hours, with a mean of 4.5 hours $(\mathrm{SD}=0.7 \mathrm{~h})$. As may be seen these values are rather similar to those calculated for toluene in alveolar air (mean $3.8 \mathrm{~h}$; range $2 \cdot 6-6 \mathrm{~h}$ ).

\section{Conclusion}

Our data showed that morning and afternoon blood toluene concentrations correlated better than alveolar toluene concentrations. Moreover, the blood toluene concentrations measured at the end of the workshift were highly correlated with the environmental toluene : concentration measured during the entire workshift. Therefore, it seems from this that, in the evaluation of occupational toluene exposure, the analysis of the

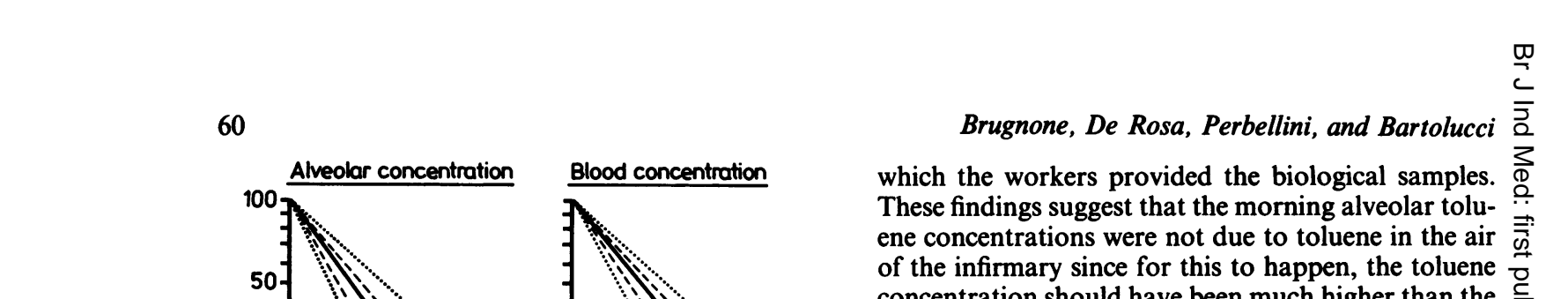


blood samples collected the morning after gives a more reliable index than the analysis of the alveolar air collected at the same time. On the other hand alveolar and blood toluene concentrations indicated a similar clearance rate and half life.

In the group of workers studied the toluene concentrations found in the morning alveolar air and blood suggest that the interval between two consecutive workshifts is insufficient for the complete elimination of the toluene absorbed during the workshift. This means that occupational exposure to toluene $(146 \mu \mathrm{g} / \mathrm{l}$; table 1) below the present TLV can lead to accumulation. We must bear in mind that the half life of toluene in fat tissue is about 1.5 days ${ }^{101617}$ and therefore fat tissue can release toluene into the blood stream for a long time after the end of exposure.

This work was in part supported by the Italian National Council (CNR): finalised project on preventive and rehabilitative medicine, subproject SP5, toxicological risk, grant No 83.0258056.

\section{References}

${ }^{1}$ Astrand I, Ehrner-Samuel H, Kilbon A, Ovrum P. Toluene exposure. I. Concentration in alveolar air and blood at rest and during exercise. Work Environ Health 1972;9:119-30.

${ }^{2}$ Veulemans H, Masschelein R. Experimental human exposure to toluene. Factors influencing the individual respiratory uptake and elimination. Int Arch Occup Environ Health 1978;42:91-103.

${ }^{3}$ Veulemans H, Masschelein R. Experimental human exposure to toluene. Toluene in venous blood during and after exposure. Int Arch Occup Environ Health 1978;42:105-17.

${ }^{4}$ Carlsson A. Exposure to toluene. Uptake, distribution and elimination in man. Scand J Work Environ Health 1982;8:43-55.

${ }^{5}$ Szadkowski D, Pett R, Angerer J, Manz A, Lehnert G. Chronische
Losungsmittelbelastung am Arbeitsplatz: II. Schadstoffspiegel im Blut und Metabolitenelimination im Harn in ihrer Bedeutung als Uberwachungskriterien bei toluolexponierten Tiefdruckern. Internationale Archiv für Arbeitzmedizin 1973;31:265-76.

${ }^{6}$ Ovrum P, Hultengren M, Lindqvist T. Exposure to toluene in a photogravure printing plant: concentration in ambient air and uptake in the body. Scand J Work Environ Health 1978;4:237-45.

${ }^{7}$ Konietzko H, Keilbach J, Drysch K. Cumulative effects of daily toluene exposure. Int Arch Occup Environ Health 1980;46:53-8.

${ }^{8}$ Angerer J, Behling K. Chronische Losungsmittelbelastung am Arbeitsplatz: IX. Ein Verfahren zur Evaluierung von Grenzwerten fur Parameter der inneren Belastung am Beispiel der Toluolexposition. Int Arch Occup Environ Health 1981;48: $137-46$.

9 Apostoli P, Brugnone F, Perbellini L, Cocheo V, Bellomo ML, Silvestri R. Biomonitoring of occupational toluene exposure. Int Arch Occup Environ Health 1982;50:153-68.

${ }^{10}$ Brugnone F, Perbellini L, Apostoli P, Locatelli M, Mariotto P. Decline of blood and alveolar toluene concentrations following two accidental human poisonings. Int Arch Occup Environ Health 1983;53:157-65.

${ }^{11}$ Droz PO, Berode M, Boillat MA. Biological monitoring and health surveillance of rotogravure printing workers exposed to toluene. In: Ho MH, Dillon HK, eds. Biological monitoring of exposure to chemicals. Vol 1. Organic compounds. New York: Wiley \& Sons, Inc (in press).

${ }^{12}$ International Workshop on Toxicology of Benzene, Paris: 9-11 November 1976. Int Arch Occup Environ Health 1978;41:65-76.

${ }^{13}$ Lauwerys R. Toluene. In: Industrial health and safety. (Human biological monitoring of industrial chemicals series.) Luxembourg: Commission of the European Communities, 1983:160-75.

${ }^{14}$ NIOSH manual of analytical methods. 2nd ed. Part II. Standards completion program validated methods. Cincinnati: DHEW (NIOSH), 1977: S343-1, S343-8. (Publication No 77-157-C.)

${ }^{15}$ Krotoszynski BK, Bruneau GM, O'Neill HJ. Measurement of chemical inhalation exposure in urban population in the presence of endogenous effluents. J Anal Toxicol 1979;3:225-34.

${ }^{16} \mathrm{Cohr}$ KH, Stokholm J. Toluene - a toxicologic review. Scand $J$ Work Environ Health 1979;5:71-90.

${ }^{17}$ Carlsson A, Ljungquist E. Exposure to toluene. Concentration in subcutaneous adipose tissue. Scand $J$ Work Environ Health 1982;8:56-62. 